\title{
A poética de Augusto dos Anjos e a neuropsiquiatria no fin de siècle
}

\section{The poetry of Augusto dos Anjos and fin de siècle neuropsychiatry}

\section{Leonardo Cruz de Souza}

Neurologista, Serviço de Neurologia/Departamento de Clínica Médica (CLM)/Faculdade de Medicina (FM)/Universidade Federal de Minas Gerais (UFMG).

Belo Horizonte - MG - Brasil

leocruzsouza@hotmail.com

\section{Ana Carolina Sarquis Salgado}

Psiquiatra, Grupo de Neuropsiquiatria/Hospital das Clínicas/UFMG. Belo Horizonte - MG - Brasil

acssalgado@gmail.com

\section{Maurício Viotti Daker}

Psiquiatra, Departamento de Saúde Mental/FM/UFMG.

Belo Horizonte - MG - Brasil

viotti@ymail.com

\section{Francisco Cardoso}

Neurologista, Serviço de Neurologia/Departamento de Clínica Médica (CLM)/FM/UFMG.

Belo Horizonte - MG - Brasil

cardosofe@terra.com.br

\section{Antônio Lúcio Teixeira}

Neurologista e psiquiatra, Serviço de Neurologia/CLM/FM/UFMG. Belo Horizonte - MG - Brasil

altexr@gmail.com

Recebido para publicação em 24.10.2016.

Aprovado para publicação em 03.04.2017.

http://dx.doi.org/10.1590/S0104-59702018000100010
DE SOUZA, Leonardo Cruz et al. A poética de Augusto dos Anjos e a neuropsiquiatria no fin de siècle. História, Ciências, Saúde - Manguinhos, Rio de Janeiro, v.25, n.1, jan.-mar. 2018, p.163-179.

\section{Resumo}

O paraibano Augusto dos Anjos ocupa um lugar singular na literatura brasileira, sendo difícil alinhá-lo a um estilo literário estrito. Sua poesia é marcada por versos angustiados, pela dimensão existencial e pelo vocabulário repleto de termos científicos. A obra do poeta se reveste de interesse neuropsiquiátrico, seja pela abundante presença de termos relacionados, seja por refletir concepções neurocientíficas da transição entre os séculos XIX e XX. Este trabalho revisita sua produção literária, com duplo foco: primeiro, busca identificar como sua poesia repercute o viés organicista da psiquiatria dessa época, conforme geralmente personificado na figura de Emil Kraepelin; segundo, tenta explorar os conteúdos ideológicos presentes na obra, como a perspectiva darwinista e a tensão entre o dualismo e o monismo materialista.

Palavras-chave: Augusto dos Anjos (18841914); neuropsiquiatria; Emil Kraepelin (1856-1926).

\section{Abstract}

Augusto dos Anjos, from Paraíba, Brazil, occupies a singular place in Brazilian literature, defying alignment with any one literary style. His poetry is marked by anguished verse, by existential dimensions and a vocabulary replete with scientific terms. His work is of great interest to neuropsychiatry, not just for the abundance of related terms, but also because it reflects conceptions from neuroscience at the turn of the twentieth century. This study focuses on his literary output from a dual perspective: by identifying how his poetry reflects the organicist tendency in psychiatry at the time, as generally personified in the figure of Emil Kraepelin, and by exploring the ideological content of the work, like the Darwinist perspective and the tension between dualism and materialistic monism.

Keywords: Augusto dos Anjos (1884-1914); neuropsychiatry; Emil Kraepelin (18561926). 


\begin{abstract}
$\mathrm{A}^{\mathrm{s}}$ o postular que "um sinal de que um livro tem valor literário é que este aceita diversas leituras", Auden (1993, p.400) estabeleceu um marco distintivo do valor de um texto literário. Eu, do escritor Augusto dos Anjos, é um exemplo emblemático da obra cujas possibilidades de leituras se abrem em um caleidoscópio, permitindo abordagens oriundas de diferentes disciplinas, não apenas da literatura, mas também da filosofia, da psicanálise e da historiografia. Em um registro circunscrito, a obra atrai a atenção do leitor sob um prisma neurocientífico, pela peculiar escolha vernacular, plena de termos relacionados à neuropsiquiatria. Em um sentido mais amplo, a produção de Augusto dos Anjos reflete as concepções científicas do seu próprio tempo, período que pode ser referido como fin de siècle, marcado por diversos movimentos culturais (como o simbolismo e a art nouveau) e pelo cientificismo, que influenciaram grandemente as artes entre as décadas finais do século XIX e o início da Primeira Guerra Mundial. O presente texto tem como objetivo analisar as referências neurocientíficas presentes na obra do poeta à luz de sua biografia, associando-as aos conceitos da neuropsiquiatria vigentes à sua época.

Para tanto, o artigo fará, inicialmente, uma breve apresentação biográfica de Augusto dos Anjos. A seguir, exporá a presença de vocábulos de cunho neurocientífico na sua poesia, para, então, discutir a questão de como as referências neuropsiquiátricas na obra anjelista se articulam com a concepção neuropsiquiátrica do fin de siècle, da qual a psiquiatria kraepelineana é considerada influente representante (Muñoz, 2015). Nesse item, será brevemente abordado o contraponto entre a visão de loucura na obra de dos Anjos e aquela presente em escritores como Machado de Assis e Lima Barreto. Posteriormente, será explorado o viés darwinista presente na poesia de Augusto dos Anjos, a partir de referências a autores como Herbert Spencer e Ernst Haeckel. Por fim, tratar-se-á da tensão ideológica existente na produção do poeta, que dialoga com duas visões díspares do problema mentecérebro: o monismo e o dualismo.
\end{abstract}

\title{
Vida e obra
}

Augusto dos Anjos nasceu em 1884 em um engenho de açúcar em Pau d'Arco, no então estado da Paraíba do Norte. Terceiro dos seis filhos de uma família latifundiária, Augusto foi inicialmente educado pelo pai, o doutor Alexandre Rodrigues dos Anjos, bacharel em direito. Após a formação inicial, Augusto prosseguiu seus estudos no curso de humanidades do Liceu Paraibano, no qual se matriculou em 1900. Foi também em 1900 que publicou seu primeiro trabalho, o soneto "Saudade". Iniciava-se ali uma série de colaborações com jornais locais, como o Almanaque do Estado da Paraíba, O Comércio e A União, que publicariam seus versos nos anos subsequentes.

À conclusão do curso no liceu, seguiu-se o ingresso na Faculdade de Direito de Pernambuco. Tanto o curso no Liceu Paraibano (1900-1902) quanto o de Direito (19031907) foram realizados sob a modalidade de "exame vago", que permitia que os alunos não fossem assíduos, desde que se submetessem à arguição da totalidade da matéria do curso (Barbosa, 2004). Desse modo, a não ser por curtos períodos na Paraíba e no Recife, Augusto dos Anjos viveu no Engenho Pau D’Arco até os 24 anos de idade (1908). 
Foi, portanto, no Engenho Pau d'Arco que se deu parte essencial da formação intelectual de Augusto dos Anjos. Porém, a circunscrição geográfica não correspondeu a um isolamento. Ali, Augusto dos Anjos conviveu com a rica biblioteca do pai, o qual era reputado por sua grande erudição, sendo cultor de obras clássicas, além de autores de grande influência em seu tempo, como Herbert Spencer e Karl Marx (Nóbrega, 1962). A convivência com a chamada Escola do Recife também foi decisiva para a formação intelectual do poeta, influenciando-o com o positivismo de Auguste Comte, o naturalismo e o evolucionismo de Charles Darwin, o monismo materialista de Ernst Haeckel e a filosofia de Arthur Schopenhauer (Gonçalves, 2007; Nóbrega, 1962).

Foi também a partir do Engenho Pau d'Arco que Augusto dos Anjos assistiu às intensas transformações socioeconômicas que marcaram o declínio do Império. Ao longo do século XIX, paralelamente à ascensão da economia cafeeira no Sudeste, ocorre o declínio da economia nordestina, escravagista e fortemente ancorada na monocultura do açúcar. A decadência finissecular acentuou-se com os movimentos republicano e abolicionista. O impacto sobre os latifundiários nordestinos - entre os quais a família de Augusto dos Anjos - foi imenso. Aos poucos, os engenhos da família foram hipotecados e transferidos aos credores. O último a ser entregue foi o Engenho Pau d'Arco, em 1910, acontecimento que marca profundamente o poeta.

Augusto dos Anjos já tinha então renda própria, que vinha não da advocacia, carreira que jamais exerceu, mas da docência. Desde 1908, Augusto exercia o magistério particular e, desde 1909, lecionava literatura no Liceu Paraibano.

O ano de 1910 foi também movimentado pelo casamento com Ester Fialho e pela mudança para o Rio de Janeiro, em outubro. Na então capital federal, Augusto dos Anjos estabelece-se como professor de geografia na Escola Normal e no Colégio Pedro II. Porém, a mudança para a capital federal não lhe trouxe o conforto financeiro, tampouco o sonhado reconhecimento literário. À atribulação desse período, somou-se um acontecimento trágico: nasce morto o primeiro filho do poeta, em 1911.

Em 1912, aos 28 anos de idade, publica $E u$ - custeado pelo poeta, em parceria com o irmão Odilon, visto que nenhum editor aceitou publicá-lo. Eu seria seu único livro publicado em vida. É também em 1912 que nasce sua filha Glória, à qual se seguiria Guilherme, nascido em 1913.

As dificuldades financeiras no Rio de Janeiro o coagiram a aceitar o cargo de diretor de um grupo escolar em Leopoldina, na Zona da Mata de Minas Gerais. Contudo, poucos meses após chegar à cidade, Augusto dos Anjos veio a falecer, em 1914, vítima de uma possível pneumonia, quando tinha apenas 30 anos de idade. Sua morte foi pouco repercutida pela imprensa da capital.

A poesia de Augusto dos Anjos ocupa um lugar singular na literatura brasileira. Seus versos não se alinham ao parnasianismo, ainda vigoroso à época do poeta, nem ao simbolismo de Cruz e Souza (1861-1898) e de Alphonsus de Guimarães (1870-1921), nem a qualquer outro movimento literário específico (Bosi, 1994). O enquadramento do poeta como representante da "poesia científica" também é um tema controverso (Albuquerque, 1995; Sabino, 2006). Trata-se, assim, de uma obra poética de difícil classificação, podendo 
ser considerada "pré-modernista" não apenas por um critério meramente cronológico, mas também pela modernidade da poesia, posição defendida, entre outros, por Ferreira Gullar (Ferreira, 2011; Gonçalves, 2007). Embora a discussão acerca da classificação da obra de Augusto dos Anjos fuja ao escopo e aos objetivos deste trabalho, cumpre assinalar que essa classificação "pré-modernista" não é unânime entre os críticos, podendo ser questionada sob um prisma historiográfico (Antônio, 2004; Rubert, 2007; Ferreira, 2011).

O caráter singular da poesia anjelista não está no seu aspecto formal, marcado pelos versos decassílabos sáficos, mas na peculiar escolha vocabular e no conteúdo temáticoideológico (Ferreira, 2011; Gonçalves, 2007; Rubert, 2007). A pletora de termos científicos, o pessimismo e a angústia flagrantes, os diálogos com o positivismo, com o evolucionismo e com o monismo conferem aos versos de Augusto dos Anjos uma assinatura poética personalíssima e sem par na literatura brasileira (Bosi, 1994).

Nesse universo singular, encontram-se também versos que podem ser revisitados pelo prisma da neuropsiquiatria e da historiografia dos saberes psi, objeto do presente texto.

\section{O léxico neurocientífico}

Um dos traços mais singulares dos versos anjelistas é o abundante recurso à terminologia científica, sobretudo neurocientífica, que confere um aspecto controvertido à sua obra, cujo vocabulário, desde a publicação dos primeiros versos, é contestado como sendo de "mau gosto" (Bosi, 1994, p.288) ou de um "exotismo estapafúrdio" (Barbosa, 2004, p.74). O recurso abundante a termos científicos e o caráter pessimista e angustiado dos versos contrapõem nitidamente Augusto dos Anjos aos parnasianos e aos simbolistas, o que pode parcialmente explicar a estranheza com a qual $E u$ foi recebido e a discreta repercussão de sua publicação em 1912. No entanto, é justamente o vernáculo peculiar, que chocou os poetas parnasianos contemporâneos, um dos atrativos de sua obra, responsável por sua popularização e reconhecimento póstumos, especialmente a partir dos anos 1970, quando diversos ensaios críticos sobre o poeta foram publicados (Bosi, 1994).

O pródigo emprego de terminologia científica suscita o debate da classificação de Augusto dos Anjos como "poeta científico" (Sabino, 2006). A poética científica, alinhada com a decadência do romantismo e inspirada pelas fervilhantes teorias científicas do século XIX, surgiu como uma proposta estética que dialogava com as ideias positivistas. O movimento da nova poesia se iniciou no Brasil no âmbito da Escola do Recife, movimento cultural finissecular considerado irradiador da doutrina positivista (Sabino, 2006). A proposta principal do novo estilo poético seria a recriação de elementos materiais dentro da poesia, rompendo com a estética romântica e eliminando os assuntos proibidos: surge então a poesia do prosaico, do feio, do pedantismo vocabular. Nessa perspectiva, a escolha vernacular sui generis de Augusto dos Anjos, rica em termos neuropsiquiátricos, poderia ser uma opção estética deliberada e consciente, embora não nos estejam claras as razões e as maneiras pelas quais se deu a apropriação de um léxico neurocientífico por parte do poeta.

A nova estética teria sido, aliás, duramente questionada pelos intelectuais da época, que não acreditavam ser possível estreitar as relações entre poesia e ciência (Sabino, 2006; Soares, 2004). Nesse contexto, o poeta Martins Júnior, no manifesto de 1883 intitulado "A poesia 
científica", cita Spencer: "não só a ciência serve de base à pintura, à escultura, à música e à poesia, como também a ciência é por si mesma poesia" (citado em Sabino, 2006, p.22).

Contudo, o alinhamento de Augusto dos Anjos como poeta "científico" não é feito sem óbices. Enquadrá-lo sob a etiqueta da "poesia científica" pode ser reducionista. Ele se diferencia de autores "científicos" como Martins Júnior, que, segundo Albuquerque (1995, p.89), "o que fazia era reduzir a versos teorias científicas, de preferência positivistas". De fato, a obra de Augusto não pode ser sintetizada como uma versificação de teorias científicas, visto que o autor imiscui nos seus versos reflexões existenciais, cósmicas e filosóficas, indo muito além da mera tipificação "científica".

Um inventário não sistemático de termos neurocientíficos presentes em Augusto dos Anjos inclui: alucinações ("Monólogo de uma sombra", Anjos, 2004, p.95), cerebralidade ("Os doentes", Anjos, 2004, p.125), convulsões ("Alucinação à beira-mar", Anjos, 2004, p.155), delirium tremens ("As cismas do destino", Anjos, 2004, p.108), encéfalo ("Tristeza de um quarto minguante", Anjos, 2004, p.172), epilepsia ("A um epiléptico", Anjos, 2004, p.200), intracefálica ("Monólogo de uma sombra", Anjos, 2004, p.94), centros medulares ("Decadência", Anjos, 2004, p.139), massa encefálica ("Mistérios de um fósforo", Anjos, 2004, p.177), subconsciência ("Numa forja", Anjos, 2004, p.197), microcéfalo ("Os doentes", Anjos, 2004, p.127), tálamo (“Os doentes", Anjos, 2004, p.123), vértebras ("As cismas do destino", Anjos, 2004, p.113), entre outros. Porém, mais do que as acepções técnicocientíficas desses termos em si mesmas, o interesse da leitura "neurocientífica" de Augusto dos Anjos recai sobre os aspectos conceituais inseridos na sua obra.

\section{A neuropsiquiatria em Augusto dos Anjos}

A neuropsiquiatria viveu seu apogeu entre os séculos XIX e XX, quando se confundiam a psiquiatria e a neurologia, especialmente na França e na Alemanha, em que a especialidade era referida com o termo de Nervenheilkunde ("medicina dos nervos"), e o especialista denominado Nervenartz ("médico dos nervos", termo ainda de amplo uso) (Daker, 2012). Entre seus precursores, Wilhem Griesinger (1817-1869) é reconhecido como figura de vulto entre os psiquiatras dedicados ao estudo do cérebro, sendo um dos expoentes da neuropsiquiatria na segunda metade do século XIX (Alexander, Selesnick, 1980). Ainda que considerasse as causas psíquicas as mais comuns entre todas as variadas causas de doença mental, Griesinger (citado em Alexander, Selesnick, 1980, p.208) se preocupava com o órgão em que o acometimento se daria:

o primeiro passo para o conhecimento dos sintomas (da insanidade) é sua localização: a que órgão pertencem as indicações; que órgão deve necessária e invariavelmente estar doente quando há loucura? ... Fatos fisiológicos e patológicos mostram-nos que este órgão só pode ser o cérebro, portanto, primordialmente e em todos os casos de doença mental, reconhecemos uma ação mórbida daquele órgão.

De modo similar a Griesinger, o britânico Henry Maudsley (1835-1918), o alemão Carl Wernicke (1848-1905) e o vienense Theodor Meynert (1833-1992) também sustentavam a organicidade das doenças psiquiátricas (Alexander, Selesnick, 1980). Essa visão organicista 
das doenças psiquiátricas é fortemente tributária dos avanços no conhecimento da estrutura e da neurofisiologia cerebrais, ocorridos nas décadas finais do século XIX e no início do XX. De fato, é nesse período que descobertas fulcrais foram estabelecidas nas neurociências, como a proposição do conceito de neurônio por Heinrich von Waldeyer (1836-1921), em 1891, ou a demonstração da etiologia infecciosa da paralisia geral, a neurossífilis.

É nesse cenário que emerge Emil Kraepelin (1856-1926), psiquiatra de proa nesse viés organicista da neuropsiquiatria finissecular. Esse autor teve papel central na busca de doenças mentais naturais específicas, para as quais corresponderiam causas e achados neuropatológicos próprios (Hoff, 2009). É contraposto, assim, aos pressupostos psicogênicos freudianos (Nunes, 2010). Krapelin exerceu enorme influência na psiquiatria, representando, na neuropsiquiatria, o apogeu da ciência prussiana, em um processo que se iniciou na década de 1860, com a emergência da Alemanha como potência econômica, militar e científica, sob a égide de Bismarck. Nas décadas subsequentes, a neuropsiquiatria incorporou descobertas oriundas da neurologia e da neuropatologia, com os trabalhos de Pick, Alzheimer, Nissl, entre outros. Vigoroso até meados do século XX, o termo neuropsiquiatria cedeu com as autonomizações da psiquiatria e da neurologia (Daker, 2012), embora persista como especialidade na medicina austro-germânica.

No Brasil, a passagem do século XIX para o XX é também um período marcante na história da neuropsiquiatria, reverberando os grandes debates que ocorriam nos principais centros europeus, notadamente na França e na Alemanha (Birman, 2010; Muñoz, 2015). O discurso neurocientífico da época era dominado pela busca de uma racionalidade que vinculava sinais e sintomas a lesões topográficas orgânicas (Nunes, 2010). Nesse contexto, cumpre destacar o papel de Juliano Moreira (1873-1933) que, influenciado por Kraepelin, funda a psiquiatria científica no Brasil, implementando concepções organicistas na medicina alienista brasileira (Nunes, 2010).

Ao longo de sua carreira, Juliano Moreira manteve importantes colaborações com colegas internacionais, especialmente alemães (Facchinetti, Cupello, Evangelista, 2010; Facchinetti, Muñoz, 2013; Muñoz, 2015; Oda, Dalgalarrondo, 2000). Em um esforço de internacionalizar a psiquiatria brasileira, Moreira instalou laboratórios de patologia e de bioquímica no asilo psiquiátrico, reestruturou o corpo clínico e implementou esforços para coletar dados clínicos e diagnósticos dos pacientes internados (Muñoz, 2015; Oda, Dalgalarrondo, 2000). Além disso, a criação da primeira revista nacional ligada à "medicina mental" se deu também em 1905 e sob o comando de Moreira. Os Arquivos Brasileiros de Psiquiatria, Neurologia e Ciências Afins reproduziram durante três décadas artigos de eminentes médicos brasileiros e estrangeiros, principalmente aqueles relacionados às práticas e diagnósticos realizados no próprio Hospício Nacional (Facchinetti, Cupello, Evangelista, 2010). As publicações bimestrais ou trimestrais forneciam uma oportunidade para debates por vezes intensos incluindo réplicas e tréplicas - acerca das diversas correntes da neuropsiquiatria da época (Facchinetti, Cupello, Evangelista, 2010).

Para Kraepelin e para Juliano Moreira, as chamadas doenças mentais eram exceções biológicas passíveis de ser observadas na dimensão orgânica dos indivíduos (Venancio, jul.dez. 2005). Ao assumir, em 1905, a direção do Hospício Nacional dos Alienados, então a 
principal instituição psiquiátrica do país, Juliano Moreira contribui decisivamente para a mudança paradigmática no referencial teórico da psiquiatria brasileira, afastando-se da tradição francesa (Muñoz, 2015; Oda, Dalgalarrondo, 2000) e aproximando-se da neuropsiquiatria krapeliniana: "Foi sem dúvida Juliano Moreira quem inscreveu de maneira sistemática o paradigma psiquiátrico de Kraepelin na totalidade do campo da psiquiatria no Brasil, marcando efetivamente a ruptura nesse campo, de forma indelével, com o que historicamente o antecedeu" (Birman, 2010, p.346). O cientificismo e o positivismo médicos passaram a marcar de forma hegemônica a leitura das perturbações mentais no Brasil. Pode-se dizer que um longo projeto de medicalização da loucura atingiu plena desenvoltura e se associou aos programas de higienização e ordenação sociais festejados na época pelos que enalteciam a "ordem" e o "progresso" (Engel, 2001; Facchinetti, Muñoz, 2013). Ainda que estudos recentes creditem à classificação kraepelineana uma complexa interação de fatores, tais como premissas culturais e filosóficas, práticas de pesquisa clínica, bem como contextos administrativos e institucionais, que deixaram traços nas categorias que delineou, não se nega que ele acreditasse no fundamento somático dessas categorias (Engstrom, Weber, 2007).

Assim, a obra de Augusto dos Anjos situa-se no contexto histórico de proeminência da neuropsiquiatria e na sua afirmação como ciência, nesse viés organicista daquela época. Não está claro, porém, se e como o poeta teve acesso à literatura neuropsiquiátrica desse período nem em que medida ele se apropriou dessas leituras e as integrou em sua obra. Também permanecem obscuras quais as relações de Augusto dos Anjos com a neuropsiquiatria brasileira. Esses pontos merecem ser abordados e aprofundados em pesquisas futuras.

Diversas passagens do poeta parecem vincular um estado emocional a um substrato orgânico, cerebral. É o caso, por exemplo, do trecho da carta que escreve à sua irmã, por ocasião da sua nomeação como professor substituto na cátedra de geografia, cosmografia e corografia do Brasil no Ginásio Nacional, no Rio de Janeiro, e que mitigou sua precariedade financeira: "Agora, a nomeação que acabo de ter veio sanear um pouco o meu abalado território cerebral" (Barbosa, 2004, p.72).

Semelhantemente, a vinculação de uma vivência subjetiva, psicológica, a uma base cerebral, transparece em poemas de Augusto dos Anjos (2004, p.128), como em "Os doentes": "Diabólica dinâmica daninha/Oprimia meu cérebro indefeso/Com a força onerosíssima de um peso/Que eu não sabia mesmo de onde vinha".

Em "A viagem de um vencido", Augusto (Anjos, 2004, p.209) situa a vivência de uma experiência subjetiva lúgubre a um território cerebral: "Noite. Cruzes na estrada. Aves com frio.../E, enquanto eu tropeçava sobre os paus,/A efígie apocalíptica do Caos/Dançava no meu cérebro sombrio!".

Ainda, em "Viagem de um vencido", nota-se que o poeta atribui ao cérebro e à topografia craniana as diferentes vivências emocionais passíveis da experiência humana:

A longanimidade e o vilipêndio,

A abstinência e a luxúria, o bem e o mal

Ardiam no meu orco cerebral,

Numa crepitação própria de incêndio! 
Em contraposição à paz funérea,

Doía profundamente no meu crânio

Esse funcionamento simultâneo

De todos os conflitos da matéria!

(Anjos, 2004, p.210)

A atribuição de um abalo emocional a uma base orgânica também se ressalta em o "Poema negro":
Ao terminar este sentido poema
Onde vazei a minha dor suprema
Tenho os olhos em lágrimas imersos...
Rola-me na cabeça o cérebro oco.
Por ventura, meu Deus, estarei louco?!
Daqui por diante não farei mais versos.
(Anjos, 2004, p.164)

A aproximação, em Augusto dos Anjos, entre experiência emocional e um substrato orgânico, eminentemente cerebral, articula-se, como dito, com a concepção organicista da psiquiatria de sua época. A escolha vernacular de Augusto dos Anjos, plena de termos científicos, e sua visão das perturbações da psiquê como advindas da atividade cerebral disfuncionante parecem subscrever o poder da medicina alienista, com seu vocabulário técnico, sua normatização da vida mental e sua patologização dos fenômenos mentais. Essa aproximação contrapõe-se à maneira como a loucura é retratada em escritores brasileiros do começo do século XX, como Lima Barreto e Machado de Assis.

Se há a possível chancela cientificista na obra de dos Anjos, o mesmo não se pode dizer da produção de Lima Barreto (1881-1922). Mulato, de origem humilde, vítima de preconceito racial, em constantes dificuldades financeiras, Barreto sofreu ainda o drama da institucionalização psiquiátrica devido a crises de depressão e ao alcoolismo (Bosi, 1994). Barreto foi internado duas vezes no Hospício Nacional, a primeira em 1914 e a segunda do Natal de 1919 a fevereiro do ano seguinte. Da experiência manicomial surgiria "Cemitérios dos vivos", livro em que narra suas memórias e reflexões acerca da internação psiquiátrica. O texto é um retrato cru da degradação humana na qual eram lançados os internos no hospício. A crítica aguda ao poder coercitivo médico e à medicalização excessiva da sociedade transparecem também em suas crônicas, como em "Os médicos e o espírita", datada de março de 1921 (Barreto, 2004, p.334):

A medicina é importante atividade intelectual, mas não é a única importante e não chegou a tal ponto de perfeição que os médicos tenham na cabeça ou nos livros as leis que regem as moléstias e a sua cura e a organização do Universo. Se eles fossem verdadeiramente cientistas haviam de ter dúvidas e nunca tentariam estabelecer na Terra a ditadura dos médicos, porque esta só seria válida se a medicina fosse uma verdade perfeitamente e completamente estabelecida.

A contestação do cientificismo psiquiátrico e do poderio médico é também tema central em "O alienista", de Machado de Assis (1998), publicado em 1882. O doutor Simão Bacamarte, o voluntarioso médico que chega a Itaguaí interessado no "recanto psíquico, o 
exame da patologia cerebral" (p.10), personifica o dogmatismo científico médico. Em seu furor pela psiquiatria cientificista, o doutor Bacamarte impõe um regime de terror à pacata Itaguaí, internando toda e qualquer pessoa considerada insana de acordo com critérios diagnósticos definidos de modo absolutamente arbitrário. O doutor Bacamarte advoga pela delimitação nítida entre sanidade e loucura, como ele mesmo afirma: "Supondo o espírito humano uma vasta concha, o meu fim, Sr. Soares, é ver se posso extrair a pérola, que é a razão; por outros termos, demarquemos definitivamente os limites da razão e da loucura. A razão é o perfeito equilíbrio de todas as faculdades; fora daí, insânia, insânia, e só insânia" (Assis, 1998, p.27).

Assim, o cientificismo em Augusto dos Anjos e a visão cerebral da experiência psíquica que transparece em seus textos alinham-se com o Zeitgeist médico vigente, da afirmação da psiquiatria como ciência natural de orientação somática, no que se tem designado "primeira fase da psiquiatria biológica" (Fulford et al., 2003), bem representada pelos renomados Kraepelin e seu seguidor no Brasil, Juliano Moreira. Por outro lado, esse cientificismo médico, aparentemente encampado por dos Anjos, seria criticado por outros escritores do começo do século, como Machado de Assis e Lima Barreto, que contestaram a normatização psiquiátrica e o dogmatismo científico. Além da questão da normatização organicista do saber psiquiátrico no começo do século XX, as obras de Lima Barreto e de Machado de Assis são críticas contundentes à práxis da psiquiatria da época, aos seus métodos diagnósticos e terapêuticos, bem como aos impactos pessoais e sociais resultantes da aplicação prática desses instrumentais. Décadas mais tarde, o trabalho de Michel Foucault (1926-1984) releria os conceitos de loucura e de sanidade, criticando como, ao longo da história, tais termos foram apropriados pela medicina psiquiátrica, encampando-os sob o discurso médico-científico.

\section{Diálogos científico-filosóficos na poesia de Augusto dos Anjos}

Além de repercutir a visão neuropsiquiátrica dominante, a obra do escritor paraibano reverbera os debates científico-filosóficos do seu tempo. A seguir, serão explorados dois aspectos que influíram na obra de dos Anjos: em primeiro lugar, o viés darwinista; em um segundo momento, será abordada a tensão entre o monismo materialista e o dualismo.

\section{$O$ viés darwinista}

O final do século XIX e o início do XX foram de grande efervescência no que diz respeito ao debate científico-filosófico, impulsionado notadamente pela proposição da teoria evolucionista de Charles Darwin (1809-1881). De fato, a publicação de $A$ origem das espécies, em 1859, polarizou não apenas a comunidade científica, mas também o grande público, em duas trincheiras: de um lado, os naturalistas, que advogavam que o conhecimento científico poderia explicar as leis da natureza; de outro, aqueles que, apoiados em convicções filosófico-religiosas, sustentavam que a origem e a existência da diversidade biológica decorriam da vontade e da força criadora de um Ser Supremo (Kort, 2009; Mayr, 2008). As teorias darwinianas apontavam para uma releitura dos papéis 
estabelecidos de Deus, natureza, ciência e até do próprio homem (Domingues, 2014). A defesa de conceitos como seleção natural e origem comum dos organismos forneceu substrato para a reflexão sobre a condenação dos homens ditos inferiores (indígenas americanos, por exemplo) à sua própria biologia, com inegável impacto na sociedade brasileira (Domingues, 2014; Pereira Filho, Waizbort, 2013). Não por acaso, as ideias de Darwin que encontraram maior resistência no Brasil foram justamente aquelas ligadas ao monogenismo dos mamíferos. O debate incessante poligenismo x monogenismo chegou ao imperador dom Pedro II, importante apoiador da divulgação de trabalhos científicos brasileiros no exterior e possivelmente contrário à teoria da evolução (Domingues, 2014). Leitor onívoro e observador atento das discussões do seu tempo, é muito provável que Augusto dos Anjos tenha acompanhado a recepção do darwinismo na sociedade brasileira, embora a maneira como se deu esse processo mereça ser mais bem investigada.

Além de Darwin, outros naturalistas afileiraram-se na defesa e na divulgação do evolucionismo. Dentre esses, destaca-se Ernst Haeckel (1834-1919), nome essencial na propagação do evolucionismo nas primeiras décadas do século XX. As obras de Haeckel tiveram grande penetração não apenas na Alemanha, seu país natal, como em todo o mundo (Richards, 2009). Os enigmas do Universo, uma de suas obras mais icônicas, foi traduzida em mais de 24 idiomas, tendo vendido mais de quatrocentas mil cópias antes da Primeira Guerra Mundial (Barbosa, 2004; Richards, 2009). Exímio ilustrador e notável cientista, Haeckel trouxe contribuições marcantes à ciência, como os conceitos de ecologia, de filogenia e ontogenia, propondo, por exemplo, o postulado de que, no desenvolvimento embrionário, a ontogênese recapitula a filogênese, princípio segundo o qual a embriogênese de um indivíduo retoma as etapas filogenéticas da sua própria espécie. Haeckel (citado em Mayr, 2008 , p.33) se notabilizaria pela defesa intransigente do darwinismo, como na seguinte passagem: "Vemos na descoberta de Darwin da seleção natural na luta pela sobrevivência a prova mais decisiva da validade exclusiva de causas que operam mecanisticamente em todo domínio da biologia, e vemos nisso a derrocada decisiva de todas as interpretações teleológicas e vitalistas dos organismos".

É nesse cenário que também ganha proeminência a filosofia de Herbert Spencer (18201903). Juntamente com Thomas Laycock (1812-1876), Spencer propunha uma organização evolucionista do cérebro e do sistema nervoso (Alexander, Selesnick, 1980), considerando a consciência resultante do processo evolutivo:

Se criaturas das mais elevadas espécies atingiram aquelas organizações altamente integradas, muito definidas e extremamente heterogêneas que possuem, através de modificação após modificação acumuladas durante um passado imensurável, se o desenvolvido sistema nervoso de tais criaturas adquiriu complexa estrutura e funções pouco a pouco; então necessariamente as complicadas formas de consciência, que são os correlatos dessas complexas estruturas e funções, também devem ter surgido gradativamente (Spencer, citado em Alexander, Selesnick, 1980, p.218).

Spencer, responsável por ter cunhado a expressão "sobrevivência do mais apto", teve grande influência sobre John Hughlings Jackson (1835-1911), maior neurologista britânico da segunda metade do século XIX e nome incontornável na história do pensamento neurológico (Alexander, Selesnick, 1980). 
Tanto Haeckel quanto Spencer eram familiares a Augusto dos Anjos, sendo por ele citados em alguns de seus poemas, como "Agonia de um filósofo" (Anjos, 2004, p.97), "Mater originalis" (Anjos, 2004, p.117) e "As cismas do destino" (Anjos, 2004, p.113). É também o caso de "Os doentes": "Tentava compreender com as conceptivas/Funções do encéfalo as substâncias vivas/Que nem Spencer, nem Haeckel compreenderam..." (Anjos, 2004, p.122).

No soneto escrito em homenagem póstuma ao filho falecido aos 7 meses, dos Anjos parece retomar a noção embriológica evolucionista de Haeckel, inserindo a embriologia defectiva da criança na sua própria ontogênese embriológica: "Que poder embriológico fatal/Destruiu, com a sinergia de um gigante,/Em tua 'morfogênese' de infante/A minha 'morogênese' ancestral?!" (Anjos, 2004, p.100; destaques no original).

O viés evolucionista, darwinista, de Augusto dos Anjos (2004, p.119) pode ser identificado em "O último credo", no qual ele parece assumir a própria descrença na interveniência de um Ser Supremo como sustentador da vida, aproximando-se da crença no naturalismo evolucionista:
Creio, como o filósofo mais crente, na generalidade descrente
Com que a substância cósmica evolui...
Creio, perante a evolução imensa,
Que o homem universal de amanhã vença
O homem particular que eu ontem fui!

Em suma, a leitura de naturalistas como Haeckel e Spencer pode ter contribuído para a perspectiva cientificista da poesia de Augusto dos Anjos (Barbosa, 2004; Ferreira, 2011). Esse prisma darwinista, materialista, transparece em algumas passagens do poeta, seja no viés organiscista com que se refere a vivências emocionais, seja no recurso excessivo a termos científicos, seja nas referências a conceitos evolucionistas. Entretanto, cumpre observar que a discussão acerca de uma eventual afiliação do poeta a preceitos oriundos de vertentes mais "organicistas" da psiquiatria é limitada por não ser completamente claro quais eram as leituras do poeta em termos de literatura médico-psiquiátrica.

\section{A tensão entre o monismo materialista e o dualismo em Augusto dos Anjos}

Outro aspecto que merece a atenção ao se analisar o conteúdo filosófico-científico em Augusto dos Anjos é o diálogo entre o monismo e o dualismo em sua obra.

De acordo com a filosofia monista, toda a realidade é única, havendo unidade entre todas as coisas (Ferreira, 2011). Trata-se de uma doutrina ampla que, no que diz respeito às neurociências, sustenta a não distinção (identidade) entre mente e corpo, em oposição ao dualismo cartesiano (Bennet, Hacker, 2003; Bunge, 2007). Para o monismo materialista, a psique não é uma dimensão metafísica (a alma), mas parte indissociável de uma corporalidade biológica, cerebral (Bennet, Hacker, 2003; Bunge, 2007).

O monismo é presente em Augusto dos Anjos, expressando-se não somente em um viés materialista, mas se abrindo também a uma perspectiva mística, manifestando a ideia de que todas as coisas compartilham uma mater originalis (a mônada), a qual seria também o estuário final de todas as coisas, uma vez finda a existência terrena (Gonçalves, 2007). 
Os seguintes versos do poema "Os doentes" (Anjos, 2004, p.129) se inserem em uma visão monista, vinculando o pensamento a um processo biológico subjacente, contrapondose, assim, a uma visão dualista da questão mente-cérebro: "Mas o que mais no Cosmos me entusiasma/É a esfera microscópica do plasma/Fazer a luz do cérebro que pensa".

Semelhantemente, o poema "Ideia" (Anjos, 2004, p.98) também se contrapõe ao dualismo cartesiano, inscrevendo-se em uma leitura monista e materialista:

De onde ela vem?! De que matéria bruta

Vem essa luz que sobre as nebulosas

Cai de incógnitas criptas misteriosas

Como as estalactites duma gruta?!

Vem da psicogenética e alta luta

Do feixe de moléculas nervosas,

Que, em desintegrações maravilhosas,

Delibera, e depois, quer e executa!

Vem do encéfalo absconso que a constringe,

Chega em seguida às cordas da laringe,

Tísica, tênue, mínima, raquítica ...

Quebra a força centrípeta que a amarra,

Mas, de repente, e quase morta, esbarra

No mulambo da língua paralítica!

Observa-se aqui que Augusto dos Anjos concebe o pensamento e a linguagem como resultantes de um processo biológico cerebral coordenado ("Vem do encéfalo absconso que a constringe/Chega em seguida às cordas da laringe"). Nesse aspecto, a poesia anjelista dialoga com os avanços científicos do seu próprio tempo, pois datam das décadas finais do século XIX e do início do XX os trabalhos seminais que estabeleceram claramente a relação entre funções mentais (por exemplo, a linguagem) e substratos neuroanatômicos específicos. É o caso, por exemplo, dos estudos de Paul Broca (1824-1880), que contribuíram para a elucidação das bases neurológicas das afasias. Em 1861, Broca comunicou à Société d'Anthropologie de Paris seu estudo anátomo-clínico do paciente Leborgne, que sofria de epilepsia, hemiplegia à direita e comprometimento da linguagem, com dificuldade expressiva e estereotipias verbais ("Tan tan") (Teive, Munhoz, Caramelli, 2011). Ao relacionar o deficit de linguagem com a lesão neurológica subjacente no giro frontal inferior esquerdo, Broca consolidou observações anteriores de Auburtin e de Bouillaud, galvanizando a abordagem localizacionista das funções cognitivas. O localizacionismo seria reforçado por novas descrições, como a do centro de compreensão das palavras por Carl Wernicke (1874), o centro da escrita por Exner (1881) e o centro da leitura por Déjerine (1892).

A noção do pensamento como função dependente da atividade cerebral é também explícita no poema "Martírio do artista" (Anjos, 2004, p.138): "Arte ingrata! E conquanto, em desalento,/A órbita elipsoidal dos olhos lhe arda,/Busca exteriorizar o pensamento/ Que em suas frontais células guarda!"

Nesses versos, é notável a relação estabelecida entre o pensamento e o córtex frontal, a qual já era intuída à época do poeta. Desde os trabalhos de Thomas Willis (1621-1675) 
já se considerava o córtex cerebral a estrutura que representa a base biológica de atributos psicológicos humanos. Franz Joseph Gall (1758-1828) e seu colaborador Johann Spurzheim (1776-1832) deram contribuições importantes, ainda que controvertidas, à neuroanatomia funcional (Canguilhem, 2006; Trimble, 2007). Gall atribuía habilidades como raciocínio indutivo, julgamento e planificação a regiões frontais. O grande avanço no conhecimento da neuropsicologia do lobo frontal ocorreu, porém, muitas décadas depois do falecimento do poeta, a partir do final do século XX, quando se confirmou, por meio de abordagens clínicas e experimentais, a preponderância do lobo frontal para comportamentos complexos e para o pensamento abstrato (Volle et al., 2010).

Paralelamente ao monismo materialista presente nos versos anjelistas, há neles também elementos que podem ser associados ao dualismo. De fato, não há, na poesia de Augusto dos Anjos, uma coerência temática absoluta, havendo mesmo uma interlocução entre antagonismos ideológicos (Ferreira, 2011; Gonçalves, 2007). Em "Apóstrofe à carne" (Anjos, 2004, p.182), por exemplo, observa-se uma manifesta perspectiva dualista:
E o Homem - negro e heteróclito composto, onde a alva flama psíquica trabalha, desagrega-se e deixa na mortalha o tato, a vista, o ouvido, o olfato e o gosto!
Carne, feixe de mônadas bastardas, conquanto em flâmeo fogo efêmero ardas, a dardejar relampejantes brilhos,
dói-me ver, muito embora a alma te acenda, em tua podridão a herança horrenda, que eu tenho de deixar para os meus filhos!

Nota-se aqui a insistência - recorrente em Augusto dos Anjos - na finitude decrépita da matéria biológica. Há, ainda, uma dimensão filosófica, pois é nessa carne, destinada à podridão, que trabalha a "alva flama psíquica", a qual, na morte, "desagrega-se" do corpo, abandonando nele os cinco sentidos. Uma corporalidade mortal acesa pela alma: o dualismo cartesiano encontra em Augusto dos Anjos uma poderosa representação.

A perspectiva dualista também pode ser observada em "Gemidos de arte", no qual o poeta afirma: "Mas a carne é que é humana! A alma é divina" (Anjos, 2004, p.143).

A dicotomia entre alma e mente também se faz presente em "A dança da psiquê" (Anjos, 2004, p.193), poema no qual se apresenta, inclusive, um contraponto entre pulsões instintivas e alma:

A dança dos encéfalos acesos

Começa. A carne é fogo. A alma arde. A espaços

As cabeças, as mãos, os pés e os braços

Tombam, cedendo à ação de ignotos pesos!

É então que a vaga dos instintos presos

- Mãe de esterilidades e cansaços -

Atira os pensamentos mais devassos

Contra os ossos cranianos indefesos. 
Subitamente a cerebral coreia

Para. O cosmos sintético da Ideia

Surge. Emoções extraordinárias sinto...

Arranco do meu crânio as nebulosas.

E acho um feixe de forças prodigiosas

Sustentando dois monstros: a alma e o instinto!

O diálogo entre monismo e dualismo em Augusto dos Anjos reflete um debate que se dava na própria época do escritor. Os anos finais do século XIX e o início do XX foram marcados por acalorados debates sobre o papel do cérebro nas habilidades mentais, opondo, de um lado, a abordagem localizacionista das funções cerebrais e, de outro, a perspectiva holística (conexionista). Em 1875, Charcot e Brown-Séquard se opuseram acerca da teoria localizacionista do cérebro no debate na Sociedade de Biologia em Paris, com Charcot advogando papel estrito de regiões cerebrais em funções mentais específicas e Brown-Séquard esgrimindo argumentos em favor de uma compreensão holística (não localizacionista) das funções cerebrais (Goetz, 2000). O clímax do debate entre a teoria localizacionista e a holística (conexionista) das funções cerebrais se deu entre Déjerine, que defendia a teoria localizacionista, e Pierre Marie, para quem "a terceira circunvolução frontal esquerda não tem nenhum papel especial na função da linguagem" (Roch Lecours, 1999). É famoso o episódio em que Déjerine, ofendido por um artigo de Pierre Marie, desafia-o para um duelo de espadas no Bois de Boulogne, em Paris, em 1893. O duelo foi cancelado, mas os dois neurologistas se enfrentaram em três debates na Sociedade Francesa de Neurologia em 1908 (Roch Lecours, 1999).

Esses embates entre os eminentes médicos no fin de siècle mobilizaram expressivos segmentos da sociedade e da intelectualidade europeias, trazendo à tona discussões antropológicas, sociais e religiosas em torno da relação entre cérebro e funções mentais, e da oposição entre dualismo e monismo materialista (Goetz, 2000). Arguto observador dos debates do seu tempo, Freud também contribuiu para o debate, trazendo uma perspectiva não alinhada à vertente "organicista" do entendimento das funções psíquicas, como escreveu no capítulo sobre o "inconsciente" da metapsicologia: "Todas as tentativas para adivinhar, a partir daí (as localizações cerebrais) uma localização dos processos psíquicos, todos os esforços para pensar as representações como estando armazenadas nas células nervosas fracassaram radicalmente" (citado em Canguilhem, 2006, p.188).

É também nessa época que ocorre um movimento cientificista no seio da própria psiquiatria, sob forte influência de Kraepelin, com a refutação do mesmerismo e a inscrição de fenômenos sobrenaturais, como o transe e a possessão espiritual, na nosologia psiquiátrica (Gonçalves, Ortega, 2013). O antagonismo entre o dualismo e o monismo se articula, assim, com os debates deflagrados pelo cientificismo finissecular, pela teoria evolucionista de Darwin e pelo materialismo histórico de Marx, que também abalaram os dogmas religiosos da sociedade ocidental do final do século XIX.

A própria academia brasileira não passou incólume por esse debate, como epitomado no caso do médico baiano Domingos Guedes Cabral (Pereira Filho, Waizbort, 2013). Em 1875, Guedes Cabral (1852-1883) apresentou sua tese à Faculdade de Medicina da Bahia para que lhe fosse outorgado o diploma de médico. Seu trabalho, intitulado "Funções do cérebro", 
era de cunho marcadamente darwinista e materialista, o que levou à rejeição de sua tese. Apenas após entregar outro manuscrito ("Qual o melhor tratamento para a febre amarela?") é que a referida instituição lhe conferiu o grau de médico. ${ }^{1}$ É interessante observar que a poesia de Augusto dos Anjos traz a marca das disputas filosóficas do seu tempo, com versos que se identificam ora com uma perspectiva monista, ora com uma abordagem dualista.

\section{Considerações finais: a caverna iluminada}

Este texto, em formato ensaístico, aborda a interface entre história, ciência e literatura na poesia de Augusto dos Anjos. Mais especificamente, discutimos como as referências neurocientíficas na sua obra se articulam com a concepção neuropsiquiátrica do fin de siècle, de forte influência kraepelineana e de cunho organicista. O viés darwinista na poesia anjelista também foi explorado, a partir de autores como Spencer e Haeckel. Similarmente, abordamos a tensão ambígua entre o monismo e o dualismo, presente em dos Anjos. A análise dessas diferentes questões na obra anjelista foi limitada pela dificuldade em se investigar se e como o poeta teve acesso à literatura psiquiátrica do período em análise. Esses limites analíticos podem ensejar trabalhos de pesquisa ulteriores.

Em muitos versos, a poesia de Augusto dos Anjos recorre ao termo "caverna", ora como recurso imagético de angústia e sofrimento, como em "Trevas" (Anjos, 2004, p.105): "Haverá, por hipótese, nas geenas/Luz bastante fulmínea que transforme/Dentro da noite cavernosa e enorme/Minhas trevas anímicas serenas?!"

Mas também como metáfora da mente humana, como presente nos versos de "As cismas do destino" (Anjos, 2004, p.104): “Quisera qualquer coisa provisória/Que a minha cerebral caverna entrasse/E até ao fim cortasse e recortasse/A faculdade aziaga da memória."

E nos versos de "Numa forja" (Anjos, 2004, p.196-197): "Era o ruído-clarão,/- O ígneo jato vulcânico/Que, atravessando a absconsa cripta enorme/De minha cavernosa subconsciência,/Punha em clarividência/Intramoleculares sóis acesos."

A leitura atenta da poesia anjelista permite romper com a noção de um escritor enclausurado na caverna da própria angústia e lança luzes sobre uma gruta plena de preciosas reflexões existenciais, históricas e filosóficas. Diante da riqueza lexical, dos diálogos com diversas correntes ideológicas e científicas, cumpre fazer uma réplica bissexta à depreciativa pergunta de Olavo Bilac, o qual, após ouvir um entristecido admirador de Augusto dos Anjos declamar um soneto do poeta logo após seu falecimento, perguntou: "Era este o grande poeta?" (Barbosa, 2004, p.82).

- Sim, é este o nosso grande poeta.

\section{AGRADECIMENTOS}

Somos gratos aos pareceristas pelas preciosas críticas e observações que contribuíram para o aprimoramento do presente artigo.

\section{NOTA}

${ }^{1}$ Para uma leitura aprofundada sobre o trabalho de Domingos Guedes Cabral (1852-1883) e o contexto histórico da época, ver Pereira Filho, Waizbort (2013). 


\section{REFERÊNCIAS}

ALBUQUERQUE, José Joaquim Medeiros e. O livro mais estupendo: Eu. In: Anjos, Augusto dos. Augusto dos Anjos: obra completa. Rio de Janeiro: Nova Aguilar. p.89-97. 1995.

ALEXANDER, Franz G.; SELESNICK, Sheldon T. História da psiquiatria. São Paulo: Ibrasa. 1980.

ANJOS, Augusto dos.

Eu e outras poesias. Rio de Janeiro: Bertrand Brasil. 2004.

ANTÔNIO, Jorge Luiz.

Ciência, arte e metáfora na poesia de Augusto dos Anjos. São Paulo: Navegar. 2004.

ASSIS, Joaquim Maria Machado de.

O alienista. Porto Alegre: L\&PM. 1998.

AUDEN, Wystan Hugh.

Ler. In: Auden, Wystan Hugh. A mão do artista. São Paulo: Siciliano. p.400. 1993.

BARBOSA, Francisco.

Notas biográficas. In: Anjos, Augusto dos. Eu e outras poesias. Rio de Janeiro: Bertrand Brasil. p.55-87. 2004.

BARRETO, Afonso Henriques de Lima. Toda crônica. Rio de Janeiro: Agir. 2004.

BENNET, Max R.; HACKER, Peter M.S. Philosophical foundations of neuroscience. Oxford: Blackwell. 2003.

BIRMAN, Joel.

The emergence of manic depressive psychosis as a diagnosis in Brazil. História, Ciências, SaúdeManguinhos, v.17, supl.2, p.345-371. 2010.

BOSI, Alfredo.

História concisa da literatura brasileira. São Paulo: Cultrix. 1994.

BUNGE, Mario.

Blushing and the philosophy of mind. Journal of Physiology, v.101, n.4-6, p.247-256. 2007.

CANGUILHEM, Georges.

O cérebro e o pensamento. Natureza Humana, v.1, n.8, p.183-210. 2006.

DAKER, Maurício Viotti.

História da neuropsiquiatria. In: Teixeira, Antônio Lúcio; Kummer, Arthur (Ed.). Neuropsiquiatria clínica. Rio de Janeiro: Rubio. p.13-19. 2012.

DOMINGUES, Heloísa Maria Bertol.

O darwinismo no Brasil, nas ciências naturais e na sociedade. Revista da UFMG, v.21, n.1-2, p.114-137. 2014.

ENGEL, Magali Gouveia.

Os delírios da razão: médicos, loucos e hospícios. Rio de Janeiro: Editora Fiocruz. 2001.
ENGSTROM, Eric J.; WEBER, Matthias M. Making Kraepelin history: a great instauration? History of Psychiatry, v.18, n.3, p.267-273. 2007.

FACCHINETTI, Cristiana; CUPELLO, Priscila; EVANGELISTA, Danielle Ferreira.

Arquivos Brasileiros de Psiquiatria, Neurologia e Ciências Afins: uma fonte com muita história. História, Ciências, Saúde - Manguinhos, v.17, supl.2, p.527-535. 2010.

FACCHINETTI, Cristiana; MUÑOZ, Pedro Felipe Neves de.

Emil Kraepelin and psychiatric science in Rio de Janeiro, 1903-1933. História, Ciências, SaúdeManguinhos, v.20, n.1, p.239-262. 2013.

FERREIRA, Renan Mendonça.

Conteúdos temáticos e ideológicos em Augusto dos Anjos. Dissertação (Mestrado em Letras) Universidade Federal do Espírito Santo, Vitória. 2011.

FULFORD, Kenneth W.M. et al.

Past improbable, future possible: the renaissance in philosophy and psychiatry. New York: Oxford University Press. p.1-41. 2003.

GOETZ, Christopher.

Battle of the titans: Charcot and Brown-Sequard on cerebral localization. Neurology, v.54, n.9, p.1840-1847. 2000.

GONÇALVES, Luiz Cláudio Luciano França. Mater Originalis ou Augusto dos Anjos e o caminho poético do eu. Dissertação (Mestrado em Letras) - Pontifícia Universidade Católica de Minas Gerais, Belo Horizonte. 2007.

GONÇALVES, Valéria Portugal; ORTEGA, Francisco.

A nosology for supernatural phenomena and the construction of the 'possessed' brain in the nineteenth century. História, Ciências, SaúdeManguinhos, v.20, n.2, p.373-390. 2013.

HOFF, Paul.

Historical roots of the concept of mental illness. In: Salloum, Ihsan M.; Mezzich, Juan E. (Ed.). Psychiatric diagnosis: challenges and prospects. Oxford: John Wiley. p.3-14. 2009.

KORT, Pamela.

Two painters in South America: Frederic Edwin Church and Martin Johnson Heade. In: Kort, Pamela; Hollein, Max (Ed.). Darwin: art and search for origins. Frankurt a.M.: Schirn Kunsthalle. p.12-23. 2009.

MAYR, Ernst.

Isto é biologia: a ciência do mundo vivo. São Paulo: Companhia das Letras. 2008. 
MUÑOZ, Pedro Felipe Neves de.

À luz do biológico: psiquiatria, neurologia e eugenia nas relações Brasil-Alemanha, 19001942. Tese (Doutorado em História das Ciências e da Saúde) - Casa de Oswaldo Cruz, Fundação Oswaldo Cruz, Rio de Janeiro. 2015.

NÓBREGA, Humberto.

Augusto dos Anjos e sua época. João Pessoa: Universidade da Paraíba. 1962.

NUNES, Sílvia Alexim.

Hysteria and psychiatry under Brazil's First Republic. História, Ciências, Saúde - Manguinhos, v.17, n.2, p.373-389. 2010.

ODA, Ana Maria G.R.; DALGALARRONDO, Paulo.

Juliano Moreira: um psiquiatra negro frente ao racismo científico. Revista Brasileira de Psiquiatria, v.22, n.4, p.178-179. 2000

PEREIRA FILHO, Roberto Sobreira; WAIZBORT, Ricardo.

As funções de um cérebro darwinista: Guedes Cabral e o evolucionismo de Funções do cérebro (1876). História, Ciências, Saúde - Manguinhos, v.20, n.4, p.1585-1604. 2013.

RICHARDS, Robert.

The tragic sense of Ernst Haeckel: his scientific and artistic struggles. In: Kort, Pamela; Hollein, Max (Ed.). Darwin: art and search for origins. Frankfurt a.M.: Schirn Kunsthalle. p.92-102. 2009.

ROCH LECOURS, André.

Aphasia: debates. Revue Neurologique, n.155, v.10, p.833-847. 1999.
RUBERT, Nara Marley Aléssio.

O lugar de Augusto dos Anjos na poesia

brasileira. Nau Literária, v.3, n.2, p.1-10. 2007.

SABINO, Márcia Peters.

Augusto dos Anjos e a poesia científica. Dissertação (Mestrado em Letras) - Faculdade de Letras, Universidade Federal de Juiz de Fora, Juiz de Fora. 2006.

SOARES, Orris.

Elogio de Augusto dos Anjos. In: Anjos, Augusto dos. Eu e outras poesias. Rio de Janeiro: Bertrand Brasil. p.35-54. 2004.

TEIVE, Hélio Afonso; MUNHOZ, Renato Puppi; CARAMELLI, Paulo.

Historical aphasia cases: "tan-tan", "vot-vot", and "cre nom!". Arquivos de Neuropsiquiatria, v.69, n.3, p.555-558. 2011.

TRIMBLE, Michael.

The soul in the brain: the cerebral basis of language, art and belief. Baltimore: The Johns Hopkins University Press. 2007.

VENANCIO, Ana Teresa Acatauassú. As faces de Juliano Moreira: luzes e sombras sobre seu acervo pessoal e suas publicações. Estudos Históricos, n.36, p.59-73. jul.-dez. 2005.

VOLLE, Emmanuelle et al.

Specialization of the rostral prefrontal cortex for distinct analogy processes. Cerebral Cortex, v.20, n.11, p.2647-2659. 2010. 